\title{
Power Allocation Algorithms for Massive MIMO System
}

\author{
Osman Dikmen ${ }^{1 *}$, Selman Kulaç ${ }^{2}$ \\ $1^{*}$ Duzce University, Faculty of Engineering, Departmant of Electrical Electronics Engineering, Duzce, Turkey, (ORCID: 0000-0001-8276-153X), \\ osmandikmen@duzce.edu.tr \\ ${ }^{2}$ Duzce University, Faculty of Engineering, Departmant of Electrical Electronics Engineering, Duzce, Turkey, (ORCID: 0000-0002-7737-1569), \\ selmankulac@duzce.edu.tr
}

(1st International Conference on Applied Engineering and Natural Sciences ICAENS 2021, November 1-3, 2021)

(DOI: $10.31590 /$ ejosat.1005325)

ATIF/REFERENCE: Dikmen, O., Kulaç, S., (2021). Power Allocation Algorithms for Massive MIMO System. European Journal of Science and Technology, (28), 444-452.

\begin{abstract}
Massive multiple-input multiple-output (MIMO) is still valid as an important system to increase performance of fifth generation (5G) and beyond wireless communication technologies. Spectrum efficiency (SE), high data rate and energy efficiency (EE) are among these performances. Recently, due to the increase in interconnected devices, the spread of internet of things (IoT) systems and the limited resources, various performance improvements have become inevitable. It is seen that there are various studies to realize such improvements with Massive MIMO. There are many researches especially for spectrum efficiency and energy efficiency. Because issue of energy and bandwidth problem are among the issues that need to be solved and developed first. In recent years, it is understood that power allocation algorithms have been focused on solving these two problems. In this study, researches on power allocation algorithms for MIMO systems are examined. The main points of the studies are emphasized. In addition, the comparison of three different power allocation algorithms, which will be among the basic power allocation algorithms, are carried out in terms of spectrum efficiency.
\end{abstract}

Keywords: Power allocation, 5G, Massive MIMO, Spectrum efficiency, Energy efficiency.

\section{Çok Girişli Çok Çıkışlı Sistemler için Güç Tahsisi Algoritmaları}

$\ddot{O} \mathbf{z}$

Çok büyük çok girişli çok çıkışlı sistem (Massive MIMO) beşinci nesil (5G) ve ötesi kablosuz iletişim teknolojilerinin performanslarını geliştirmek için önemli bir sistem olarak hala geçerliliğini korumaktadır. Spektrum verimliliği (SE), enerji verimliliği (EE) bu performanslar arasındadır. Son zamanlarda birbirleriyle bağlantılı cihazların artması, internet of things (IoT) sistemlerin gün geçtikçe yayılması ve buna rağmen kaynakların sınırlı olmasından dolayı çeşitli performans geliştirmeleri kaçınılmaz olmuştur. Massive MIMO ile birlikte bu tür iyileştirmeleri gerçekleştirmek için çeşitli çalışmaların olduğu görülmektedir. Özellikle spektrum verimliliği ve enerji verimliliği için birçok araştırmalar mevcuttur. Çünkü enerji konusu ve bant genişliği problemi ilk olarak çözülmesi ve geliştirilmesi gereken konular arasındadır. Son yıllarda bu iki problemin çözümüne yönelik güç tahsisi algoritmalarına odaklanıldığı anlaşılmaktadır. $\mathrm{Bu}$ çalışmada, güç tahsisi algoritmaları hakkındaki araştırmalar incelenmiştir. Çalışmaların temel noktaları üzerinde durulmuştur. Ayrıca temel güç tahsisi algoritmaları arasında yer alacak üç farklı güç tahsisi algoritmasının birbirleri arasında kıyaslaması spektrum verimliliği açısından gerçekleştirilmiştir.

Anahtar Kelimeler: Güç tahsisi, 5G, Çok girişli çok çıkışlı sistem, Spektrum verimlilik, Enerji verimliliği.

* Corresponding Author: osmandikmen@duzce.edu.tr 


\section{Introduction}

Wireless communication technologies become increasingly popular. Massive MIMO is a communication method which uses a large number of inputs and outputs that helps these advances, thanks to multiple antenna equipment on the receiving and transmitting side. Especially with the developments such as smart cities, industrial breakthroughs, devices communicating with each other and their applications, the importance of spectrum efficiency (SE) and energy efficiency (EE) has increased day by day. That is, with the increase in user data, limited spectrum resources should be used effectively. In addition, due to the fact that the energy resources are not infinite, the efficiency of the technologies whose use is increasing should be kept in the foreground.

Massive MIMO studies continued to increase day by day with the study in (Marzetta, 2010). It attracts the attention of researchers in terms of the benefits it provides. It has an important place in improving the $\mathrm{SE}$ and $\mathrm{EE}$ of $5 \mathrm{G}$ and beyond technologies (Boccardi et al., 2014). Various studies on this subject are available in the literature. Massive MIMO is a technique that might be used in 5G networks due to its advantages (Marzetta, 2010), (Rusek et al., 2013), (Larsson et al., 2014) and (Ngo et al., 2013) in improving efficiency of spectrum and energy (Boccardi et al., 2014), (Wang et al., 2014). To solve Massive MIMO's complexity problem, linear detectors such as maximum ratio combining (MRC), zero forcing (ZF) or minimum mean-square error (MMSE) have been developed (Rusek et al., 2013) and (Ngo et al., 2013).

Power allocation algorithms have recently been a hot topic in the Massive MIMO community as a way to enhance SE and EE. Due to limited bandwidth and growing user density, SE is a popular metric in communication systems. In Time DivisionLong Term Evolution-Advanced (TD-LTE-A) and 5G networks, beamforming technology is utilized to increase SE and system capacity. On the basis of fulfilling user equipment (UE) needs, a suitable power allocation method can also be employed to enhance SE. There has been a lot of focus on EE in recent years, thanks to the fast growth in power usage in communication systems. Thus, power allocation is a necessary technique to improve system performance and promote energy savings. To further exploit the advantages of power allocation, more and more studies for power allocation in Massive MIMO networks have been proposed as (Liu et al., 2017) and (Björnson et al., 2016).

\subsection{Contribution of the Study}

The contributions of the study are to present performance metrics of power allocation algorithms that provide SE and EE for Massive MIMO systems. In addition, it is to identify the traditional power allocation algorithms on which the power allocation algorithms are developed. Besides, it is to create the information with which method the proposed algorithms are compared. Therefore, bringing such a study to the literature, especially for the mentioned importance of SE and EE, will encourage researchers who will work on these issues.

Besides, the comparison of new power allocation algorithms proposed in the literature is usually made with methods such as EPA, max-min fair power allocation and max product SINR power allocation. Comparison of these three basic power allocation algorithms with each other in terms of SE in Massive MIMO uplink systems was carried out.

\subsection{Organization}

The article is organized as follows. The second section explains fundamental MIMO power allocation methods. The final expressions of the equations of these algorithms are indicated. In Chapter 3, traditional power allocation algorithms -which are compared with the proposed new algorithms- are compared within themselves. For this, basic analyzes of standard power allocation techniques are demonstrated. After these analyses, simulations were performed and the results were obtained in Chapter 4. The aim here is to observe the relative states of the known power allocation algorithms compared to each other. Finally, the article was concluded in Chapter 5 and an overall evaluation was carried out.

\section{Power Allocation for MIMO Systems}

MIMO systems are a technology that emerged with the equipping of hundreds of antennas at the base station. Therefore, there are more antennas on the transmitting side compared to conventional methods. In the case of one or several antennas in conventional systems, it was relatively easy to allocate the power used. Because generally the total power was transferred to these antennas. However, after it was clearly demonstrated that MIMO systems have become increasingly essential in the development of systems and in increasing the capacities of $5 \mathrm{G}$ and beyond technologies, problems began to arise about how the total power should be used. In order to enhance MIMO capacity, the best distribution of total power to transmit antennas is an optimization issue that must be addressed (Kshetrimayum, 2017). Before this problem was considered, power was usually distributed equally to all antennas. Considering that there is such an optimization problem, different strategies have been started to be developed. Thus, it is possible to increase the capacity by allocating more power to the good ones of the MIMO channels. Therefore, CSI is important for power allocation. According to the situation of this information, strategies such as uniform power allocation and adaptive power allocation based on Water-filling (WF) are developed. In addition, various optimal power allocations are considered according to the high and low signal-to-ratio (SNR) status.

Assuming that CSI is completely known in MIMO systems, power allocation is made according to the state of the channels. The figures showing the transmit power in the downlink and uplink states for a MIMO system are indicated in the study in (Dikmen \& Kulac, 2019). Channels with good transmit power are allocated more power and channels with poor transmission power are allocated less or no power at all.

WF algorithm has been proposed to improve this issue and increase the capacity (Cheng \& Verdu, 1993). However, the WF algorithm is not sufficient for high-capacity services. For this reason, power allocation strategies are being developed, both WFbased and with other techniques. One of them is the Quality of Service (QoS) based WF algorithm (Xi Zhang \& Ottersten, 2003).

Generally, power allocation for MIMO systems can be examined under three headings as uniform (equal) power allocation, adaptive power allocation and near-optimal power allocation as shown in Figure 1 (Kshetrimayum, 2017). 


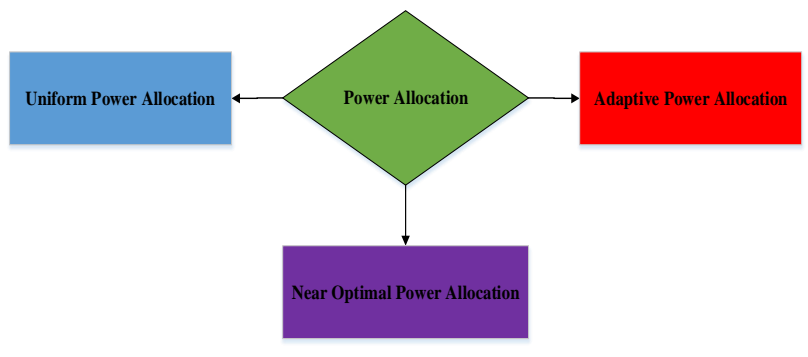

Figure 1. Power allocation scheme

\subsection{Uniform (Equal) Power Allocation}

Uniform power allocation, in other words, EPA is used in MIMO systems where CSI is known only at the receiver (Nezamalhosseini \& Chen, 2021). One of the most important factors in choosing this method is that it provides low complexity (F. Tan et al., 2018). Therefore, it was mostly preferred especially in the early days of MIMO systems. However, considering the situations where there is a limited power limit, it is important to develop different strategies. Because the same power is allocated to the user with a bad channel due to EPA, there is no effective use of power (Gandotra \& Jha, 2017).

The upper limit of the maximum capacity ratio that the communication systems can reach was determined by the study by Shannon (Shannon, 1948). Therefore, the highest point where the capacities of MIMO systems can be increased is also obvious. In a MIMO system with an $\mathrm{N}_{\mathrm{T}}$ transmit antenna and an $\mathrm{N}_{R}$ receiving antenna, assuming $\mathbf{x}$ represents the input signal vector and $\mathbf{y}$ the output signal vector, the capacity of the MIMO system are given by (Duman \& Ghrayeb, 2007), ('MIMO Syst. Theory Appl.', 2011):

$$
C=H(Y)-H(N),
$$

where $\boldsymbol{H}(\boldsymbol{Y})$ and $\boldsymbol{H}(\boldsymbol{N})$ in this expression are the entropy of the received signal and the noise signal, respectively. $\mathbf{R}_{\mathbf{x}}=\mathrm{E}\left\{\mathbf{x x}^{H}\right\}$, $\mathbf{R}_{\mathbf{n}}=\mathrm{E}\left\{\mathbf{n} \mathbf{n}^{H}\right\}$ and $\mathbf{R}_{\mathbf{y}}=\mathrm{E}\left\{\mathbf{y} \mathbf{y}^{H}\right\}$ represent the covariance matrix of transmitted signal, noise signal and received signal, respectively. In this case, $\rho$ represents SNR is given as ('MIMO Syst. Theory Appl.', 2011):

$$
\mathbf{R}_{\mathbf{y}}=\mathrm{E}\left[\mathbf{y}^{H} \mathbf{y}\right]=\rho \mathbf{H}^{H} \mathbf{R}_{\mathbf{x}} \mathbf{H}+\boldsymbol{I}_{\boldsymbol{N}_{\boldsymbol{R}}}
$$

In line with this information, the capacity expression can be rewritten as

$$
\boldsymbol{C}=\log _{2} \operatorname{det}\left(\rho \mathbf{H}^{H} \mathbf{R}_{\mathbf{x}} \mathbf{H}+\boldsymbol{I}_{\boldsymbol{N}_{\boldsymbol{R}}}\right) .
$$

Also, since $\mathbf{R}_{\mathbf{x}}$ is the covariance matrix of the transmitted signal, this expression can be represented as follows (Kshetrimayum, 2017).

$$
\mathbf{R}_{\mathbf{x}}=\frac{\mathrm{P}}{\mathrm{N}_{\mathrm{T}}} \mathbf{I}_{\mathrm{N}_{\mathrm{T}}} \text {. }
$$

As a result of these equations, the capacity expression takes the form expressed in (Vucetic \& Yuan, 2003).

$$
\boldsymbol{C}=\log _{2} \operatorname{det}\left(\boldsymbol{I}_{\boldsymbol{N}_{\boldsymbol{R}}}+\frac{\mathrm{P}}{\mathrm{N}_{\mathrm{T}} \sigma^{2}} \mathbf{H}^{H} \mathbf{H}\right)
$$

\subsection{Adaptive Power Allocation}

Adaptive power allocation using the WF method is commonly used in MIMO systems when CSI is known on both the receiving and transmitting sides (Kshetrimayum, 2017). Knowing the CSI in the transmitter is possible with a feedback system. Such a MIMO system is also called closed loop (Kshetrimayum, 2017). Thanks to the WF algorithm, more power can be allocated to those with good channel status and less power to those with bad channel status.

WF algorithm aim is to allocate more power to channels with high SNR ('MIMO Syst. Theory Appl.', 2011). The total power is allocated to the antennas based on the eigenvalues of the channel matrix (Ivanis \& Drajic, 2003). In this way, maximum capacity can be achieved with WF in MIMO systems where CSI is known at the receiver and transmitter (Yoshimoto \& Hattori, 2007).

$\mathrm{P}_{i}$ i-th channel power, $\lambda_{i} \quad \mathbf{H}^{H} \mathbf{H}$ matrix eigenvalues and $\mathbf{H}$ channel matrix rank $\mathrm{r}$; channel capacity can be written as (Ivanis \& Drajic, 2003)

$$
\boldsymbol{C}=\sum_{i=1}^{r} \log _{2}\left(1+\frac{\mathrm{P}_{i} \lambda_{i}}{\sigma^{2}}\right)
$$

By choosing $\mathrm{P}_{i}$ appropriately, it is ensured that the capacity is maximum. WF algorithm

$$
\sum_{i=}^{N_{T}} \mathrm{P}_{i}=\mathrm{P}
$$

performed under power constraint. Here $P$ is the total power. Due to the WF algorithm, $\mathrm{P}_{i}$ is given as follows (Yoshimoto \& Hattori, 2007).

$$
\mathrm{P}_{i}=\left(\mu-\frac{\sigma^{2}}{\lambda_{i}}\right)^{+}
$$

Where,

$$
(a)^{+}=\left\{\begin{array}{ll}
a, & a>0 \\
0, & a \leq 0
\end{array}\right. \text {. }
$$


If the Lagrange multipliers method is applied to the expression in equation (6) as in (Prayongpun \& Raoof, 2007) and (Khalighi et al., 2001), the new expression takes the form in ('MIMO Syst. Theory Appl.', 2011).

$$
Z=\sum_{i=1}^{r} \log _{2}\left(1+\frac{\mathrm{P}_{i} \lambda_{i}}{\sigma^{2}}\right)+\mathrm{L}\left(\mathrm{P}-\sum_{i=}^{r} \mathrm{P}_{i}\right)
$$

Here $\mathrm{L}$ is the Lagrange multiplier. $\mathrm{P}_{i}$ is found by equating the partial derivatives of Equation (11) to zero (Vucetic \& Yuan, 2003). Hence,

$$
\begin{gathered}
\frac{\delta Z}{\delta \mathrm{P}_{i}}=0 \\
\frac{\delta\left\{\log _{2}\left(1+\frac{\mathrm{P}_{i} \lambda_{i}}{\sigma^{2}}\right)-\mathrm{LP}_{i}\right\}}{\delta \mathrm{P}_{i}}=0 \\
\frac{1}{\ln 2} \frac{\lambda_{i} / \sigma^{2}}{1+\mathrm{P}_{i} \lambda_{i} / \sigma^{2}}-\mathrm{L}=0 .
\end{gathered}
$$

Thus, $\mathrm{P}_{i}$ in Equation (8) is obtained. $\mu$ is a constant value under total power constraint and is calculated as follows (Vucetic \& Yuan, 2003).

$$
\mu=\frac{1}{\mathrm{~L} \ln 2}
$$

Power allocation is an optimum solution thanks to the WF algorithm ('MIMO Syst. Theory Appl.', 2011). Therefore, the maximum capacity can be reached with the method to be applied according to the state of the MIMO system. Apart from WF, which offers EPA and an optimum power allocation, a near-optimal power allocation solution is also available. Below are brief considerations of near-optimal power allocation.

\subsection{Near-Optimal Power Allocation}

Optimal power allocation approaches usually require many iterations (Chang Soon Park \& Kwang Bok Lee, 2002). Because optimum power allocation with adaptive solution approach is a multi-purpose non-convex problem. Therefore, the computational complexity is high (Hu et al., 2014). Due to this convex problem, near-optimal power allocation algorithms are being developed as a simpler method to obtain an analytical solution (Wubben \& Lang, 2008). The computational complexity in optimal power allocation approaches is less than in simpler solutions, nearoptimal power allocation methods. The near-optimal power allocation can be converted into the following closed form expressions according to the state of the SNR level (Clerckx \& Claude Oestges, 2013).

$$
\begin{array}{ll}
\text { Low } & \boldsymbol{C}(\mathbf{H}) \stackrel{\boldsymbol{\rho \rightarrow 0}}{\longrightarrow} \log _{2}\left(1+\rho \lambda_{\max }\right) .
\end{array}
$$

Under the above condition, it would be advantageous to transfer power to the deepest part according to the situation in the WF algorithm. Thus, the total power will be transferred to stronger eigenvalues. In other words, the transfer of power to the best sub-channel is realized (Kshetrimayum, 2017).

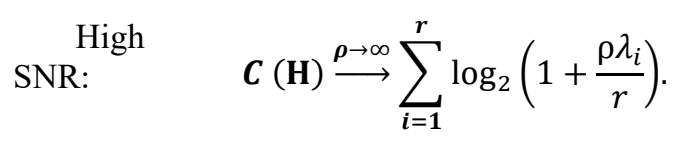

When the SNR level is high, all power is distributed among the non-zero eigenvalues (Clerckx \& Claude Oestges, 2013). This process is carried out equally

\section{Comparison of Equal, Max-Min Fairness and Max Product SINR Power Allocations Methods}

When the studies in the literature are examined, it is obvious that proposed power allocation algorithms are ineffective that the proposed power allocation algorithms are generally compared with basic methods such as EPA, max-min fairness power allocation, max product SINR power allocation. In this section, a comparison of these three basic power allocation algorithms with each other under the CDF state performance metric of SE per user (bit/s/Hz) is performed by considering uplink transmission for MRC, ZF and MMSE precoding techniques. The expressions of the symbols used in the equations mentioned in this section are shown in Table 1.

Table 1. Expression of symbols

\begin{tabular}{|l|l|}
\hline \multicolumn{1}{|c|}{ Symbol } & \multicolumn{1}{c|}{ Expression } \\
\hline$\rho_{11}, \ldots, \rho_{L K_{L}}$ & Uplink transmit power \\
\hline$\alpha_{j k}$ & Average channel gain \\
\hline$\rho_{l i}$ & Transmit power of any user \\
\hline$b_{j k}$ & Average interference gain \\
\hline$\gamma$ & SINR for Max-Min fairness power allocation \\
\hline$P_{\text {max }}^{D L}$ & Maximum uplink transmit power \\
\hline$\sigma_{U L}^{2}$ & Noise variance \\
\hline
\end{tabular}




\subsection{Equal Power Allocation}

EPA is a method in which the total power is shared equally. Information about the basic analysis of this method is given in the second part.

\subsection{Max-Min Fairness Power Allocation}

The max-min fairness power allocation technique aims to maximize the worst SINR among all users (Chaves et al., 2020). This method is used for various performance improvements in Massive MIMO systems (C. W. Tan, 2014; Van Chien et al., 2016, 2018; Yang \& Marzetta, 2017). The basic mathematical operation of the max-min fairness power allocation method can be written as follows, similar to the work in (Chaves et al., 2020).

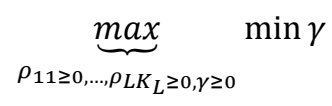

$$
\begin{aligned}
& \begin{array}{c}
\frac{\rho_{j k} \alpha_{j k}}{\sum_{l=1}^{L} \sum_{i=1}^{K_{l}} \rho_{l i} b_{l i j k}+\sigma_{U L}^{2}} \geq \gamma, j=1, \ldots, L, k \\
=1, \ldots, K_{j}
\end{array} \\
& \sum_{k=1}^{K_{j}} \rho_{j k} \leq P_{\text {max }}^{U L}, j=1, \ldots, L
\end{aligned}
$$

As a basis, the max-min fairness power allocation algorithm can be applied to the desired performance criterion. There are related studies in the related literature. These studies have been mentioned in the previous sections. The disadvantage of the maxmin fairness power allocation algorithm is that although the algorithm focuses on improving the performance of the worst user, it creates a loss in overall network efficiency of the system (Phan et al., 2009).

\subsection{Max Product SINR Power Allocation}

Max product SINR power allocation algorithm is considered in Massive MIMO systems to increase SE. Because, SE depends on a logarithmic expression of the SINR (Verenzuela et al., 2021). Detailed analyzes of the SE expressions can be examined in the study in (Björnson et al., 2017). The simplest of the power allocation methods is EPA. In addition, there is a max product SINR power allocation method that provides a balance between total SE and fairness (Bana et al., 2019). The aim is to maximize the SINR products of users across system. The mathematical expression of the max product SINR power allocation method can be written as follows, similar to the work in (Verenzuela et al., 2021).

$$
\begin{gathered}
\underbrace{\max }_{\rho_{11 \geq 0, \ldots, \rho_{L K} \geq 0}} \prod_{j=1}^{L} \prod_{k=1}^{K_{j}} \frac{\rho_{j k} \alpha_{j k}}{\sum_{l=1}^{L} \sum_{i=1}^{K_{l}} \rho_{l i} b_{l i j k}+\sigma_{U L}^{2}} \\
\sum_{k=1}^{K_{j}} \rho_{j k} \leq P_{\text {max }}^{U L}, j=1, \ldots, L
\end{gathered}
$$

\subsection{Uplink Spectrum Efficiency}

Since it is planned to examine the SE in uplink Massive MIMO systems to compare the power allocation methods, this section contains information about the uplink SE expressions. These expressions are not a new equation and detailed analysis can be found in most studies in the literature (Bashar et al., 2019; Dikmen \& Kulaç, 2021; Van Chien et al., 2018). Similar to these studies, the uplink SE expression for Massive MIMO can be written as follows, as indicated in (Marzetta et al., 2016).

$$
\mathrm{SE}_{j k}^{U L}=\left(1-\frac{\tau_{p}}{\tau_{c}}\right) \log _{2}\left(1+\operatorname{SINR}_{j k}^{U L}\right)[\mathrm{bit} / \mathrm{s} / \mathrm{Hz}]
$$

The $\tau_{c}$ symbol coherence interval is the length of the $\tau_{p}$ pilot sequences (Bana et al., 2019).

\subsection{Uplink Transmission}

In Massive MIMO uplink transmission, the expression of the received signal in cell $l$ base station $j$ can be written as specified in (Wu et al., 2018).

$$
\boldsymbol{y}_{j}=\sum_{l=1}^{L} \sum_{k=1}^{K_{l}} \mathbf{h}_{j k}^{l} s_{l k}+\mathbf{n}_{j}
$$

$\mathbf{n}_{j}$ is noise with a mean of zero and a variance of $\sigma_{U L}^{2} . s_{l k}$ is the uplink signal for user $k$ in cell $l$. The expression $\mathbb{E}\left\{\left|s_{l k}\right|^{2}\right\}=$ $\rho_{l k}$ is provided, with the strength of this signal $\rho_{l k}$. The expression in (20) can be arranged as follows, similar to the study in (Bashar et al., 2019).

$$
\boldsymbol{y}_{j}=\sum_{l=1}^{L} \sum_{k=1}^{K_{l}} \mathbf{h}_{j k}^{l} s_{l k}+\mathbf{n}_{j}
$$

$$
=\sum_{k=1}^{K_{j}} \mathbf{h}_{j k}^{j} s_{j k}+\sum_{l=1, l \neq j}^{L} \sum_{i=1}^{K_{l}} \mathbf{h}_{l i}^{j} s_{l i}+\mathbf{n}_{j}
$$

This expression, together with the $\mathbf{v}_{j k}$ combining vector to be used during transmission, is written as follows (Hawej \& Shayan, 2019).

$$
\begin{aligned}
\mathbf{v}_{j k}^{\mathrm{H}} \boldsymbol{y}_{j}=\mathbf{v}_{j k}^{\mathrm{H}} \mathbf{h}_{j k}^{j} s_{j k} & +\sum_{i=1, i \neq k}^{K_{j}} \mathbf{v}_{j k}^{\mathrm{H}} \mathbf{h}_{j i}^{j} s_{j i} \\
& +\sum_{l=1, l \neq j}^{L} \sum_{i=1}^{K_{l}} \mathbf{v}_{j k}^{\mathrm{H}} \mathbf{h}_{l i}^{j} s_{l i}+\mathbf{v}_{j k}^{\mathrm{H}} \mathbf{n}_{j}
\end{aligned}
$$

The final expression (22) of the received signal consists of the sum of desired signal, intracellular interference, intercellular interference and noise, respectively. With these results, the SINR expression for the uplink is indicated as follows (Björnson et al., 2017). Detailed evidence of these results can be seen in the references given. 


$$
\begin{aligned}
& \operatorname{SINR}_{j k}^{U L} \\
& =\frac{\rho_{j k}\left|\mathbb{E}\left\{\mathbf{v}_{j k}^{\mathrm{H}} \mathbf{h}_{j k}^{j}\right\}\right|^{2}}{\sum_{l=1}^{L} \sum_{i=1}^{K_{l}} \rho_{l i} \mathbb{E}\left\{\left|\mathbf{v}_{j k}^{\mathrm{H}} \mathbf{h}_{l i}^{j}\right|^{2}\right\}-\rho_{j k}\left|\mathbb{E}\left\{\mathbf{v}_{j k}^{\mathrm{H}} \mathbf{h}_{j k}^{j}\right\}\right|^{2}+\sigma_{U L}^{2} \mathbb{E}\left\{\left\|\mathbf{v}_{j k}\right\|^{2}\right\}}
\end{aligned}
$$

If the result in (23) is substituted in (19), the SE expression for uplink transmission is obtained for Massive MIMO systems.

\section{Numerical Results}

In this section, a comparison of the power allocation algorithms specified for SE in the uplink transmission mentioned in the previous section is performed. A multi-cell Massive MIMO system is considered and the parameters are given in Table 2. In this part where Monte Carlo simulation results are given, MRC, ZF and MMSE schemes are taken into account for a multi-cell Massive MIMO system. In this system, where the number of cells is considered to be 16 , each base station is located in the system center. The number of users in each cell is considered to randomly position as 10 . The base station has 100 antennas.

Table 2. Used parameters

\begin{tabular}{|l|c|}
\hline Parameter & Value \\
\hline Number of base station antennas, $M$ & 100 \\
\hline Number of users in each cell, $\mathrm{K}$ & 10 \\
\hline Number of base stations, $\mathrm{L}$ & 16 \\
\hline Pilot reused factor, $f$ & 2 \\
\hline Total transmit power per user, $\rho(\mathrm{mW})$ & 100 \\
\hline Length of coherence block, $\tau_{c}$ & 200 \\
\hline
\end{tabular}

The CDF of SE per user (bit/s/Hz) is considered as the performance metric used in the simulations. The CDF shows how SE changes depending on random user locations. Some users are in "good" locations and get high spectrum and other users are in "bad" locations and get lower spectrum. Different power allocation algorithms try to construct CDF curves in different ways. For example, the max-min equitable power allocation solution tries to make the curves nearly vertical to limit SE differences between users. Because the goal is to try to make the SE similar for users in good and bad locations.

Figure 2, Figure 3 and Figure 4 show the CDF of SE in a simulation with random distributions of user positions in Massive MIMO system, where the base station has 100 antennas, each cell has 10 users, and the overall number of cells is 16 , according to the MRC, ZF, and MMSE diagrams.

When the figures are examined, it can be seen that the best results are provided for the MMSE in total. It is also stated in various studies that this scheme is superior to MRC and ZF (Ngo et al., 2013) and (Björnson et al., 2017). When comparing the remaining two schemes, MRC and $\mathrm{ZF}$, it is understood that $\mathrm{ZF}$ is more effective than MRC, similar to the studies in (Chakraborty et al., 2020). When the figures are examined, the results of the SE CDF at 0.95 and 0.05 for each scheme according to the power allocation algorithms are shown in Table 3, Table 4 and Table 5, respectively. The results for the case where all users are included in the figures.

\begin{tabular}{|c|c|c|c|}
\hline \multirow{2}{*}{ Algorithm } & & \multicolumn{2}{|c|}{ CDF Point } \\
\hline & & 0.95 & 0.05 \\
\hline $\begin{array}{l}\text { Maks-Min } \quad \text { Fairness } \\
\text { Allocation }\end{array}$ & Power & $\begin{array}{l}3.867 \\
\mathrm{bit} / \mathrm{s} / \mathrm{Hz}\end{array}$ & $\begin{array}{l}0.846 \\
\mathrm{bit} / \mathrm{s} / \mathrm{Hz}\end{array}$ \\
\hline Equal Power Allocation & & $\begin{array}{l}4.687 \\
\mathrm{bit} / \mathrm{s} / \mathrm{Hz}\end{array}$ & $\begin{array}{l}0.608 \\
\mathrm{bit} / \mathrm{s} / \mathrm{Hz}\end{array}$ \\
\hline $\begin{array}{l}\text { Max Product SINR } \\
\text { Allocation }\end{array}$ & Power & $\begin{array}{l}5.759 \\
\mathrm{bit} / \mathrm{s} / \mathrm{Hz}\end{array}$ & $\begin{array}{l}0.226 \\
\mathrm{bit} / \mathrm{s} / \mathrm{Hz}\end{array}$ \\
\hline
\end{tabular}

Table 3. SE Values for MRC

\begin{tabular}{|c|c|c|c|}
\hline \multirow{2}{*}{ Algorithm } & & \multicolumn{2}{|c|}{ CDF Point } \\
\hline & & 095 & 005 \\
\hline $\begin{array}{l}\text { Maks-Min } \quad \text { Fairness } \\
\text { Allocation }\end{array}$ & Power & $\begin{array}{l}5.270 \\
\mathrm{bit} / \mathrm{s} / \mathrm{Hz}\end{array}$ & $\begin{array}{l}0.967 \\
\mathrm{bit} / \mathrm{s} / \mathrm{Hz}\end{array}$ \\
\hline Equal Power Allocation & & $\begin{array}{l}6.427 \\
\mathrm{bit} / \mathrm{s} / \mathrm{Hz}\end{array}$ & $\begin{array}{l}1.078 \\
\mathrm{bit} / \mathrm{s} / \mathrm{Hz}\end{array}$ \\
\hline $\begin{array}{l}\text { Max Product SINR } \\
\text { Allocation }\end{array}$ & Power & $\begin{array}{l}7.821 \\
\mathrm{bit} / \mathrm{s} / \mathrm{Hz}\end{array}$ & $\begin{array}{l}0.863 \\
\mathrm{bit} / \mathrm{s} / \mathrm{Hz}\end{array}$ \\
\hline
\end{tabular}

Table 4. SE Values for ZF

Table 5. SE Values for MMSE

\begin{tabular}{|lc|r|l|}
\hline \multirow{2}{*}{ Algorithm } & \multicolumn{2}{c|}{ CDF Point } \\
\cline { 3 - 4 } & & $\mathbf{0 . 9 5}$ & $\mathbf{0 . 0 5}$ \\
\hline $\begin{array}{l}\text { Maks-Min Fairness Power } \\
\text { Allocation }\end{array}$ & $\begin{array}{l}5.385 \\
\mathrm{bit} / \mathrm{s} / \mathrm{Hz}\end{array}$ & $\begin{array}{l}1.147 \\
\mathrm{bit} / \mathrm{s} / \mathrm{Hz}\end{array}$ \\
\hline Equal Power Allocation & & $\begin{array}{l}6.676 \\
\mathrm{bit} / \mathrm{s} / \mathrm{Hz}\end{array}$ & $\begin{array}{l}1.238 \\
\mathrm{bit} / \mathrm{s} / \mathrm{Hz}\end{array}$ \\
\hline $\begin{array}{l}\text { Max Product SINR } \\
\text { Allocation }\end{array}$ & Power & $\begin{array}{l}8.077 \\
\mathrm{bit} / \mathrm{s} / \mathrm{Hz}\end{array}$ & $\begin{array}{l}1.024 \\
\mathrm{bit} / \mathrm{s} / \mathrm{Hz}\end{array}$ \\
\hline
\end{tabular}




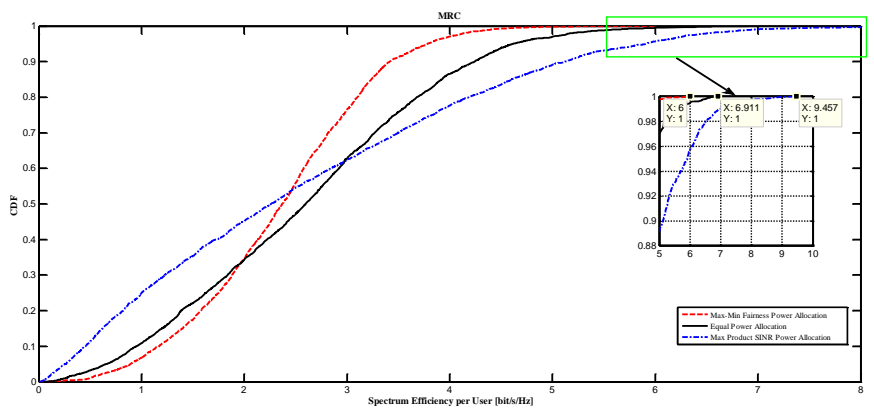

Figure 2. $\mathrm{CDF}$ of $\mathrm{SE}$ with $\mathrm{MRC}$ for $\mathrm{M}=100, \mathrm{~K}=10, \mathrm{~L}=16$



Figure 3. $\mathrm{CDF}$ of $\mathrm{SE}$ with $\mathrm{ZF}$ for $\mathrm{M}=100, \mathrm{~K}=10, \mathrm{~L}=16$

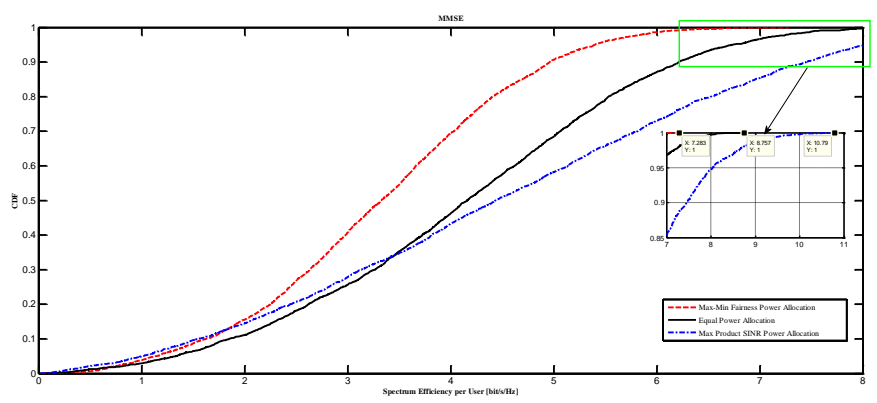

Figure 4. $C D F$ of $\mathrm{SE}$ with MMSE for $\mathrm{M}=100, \mathrm{~K}=10, \mathrm{~L}=16$

As can be seen from the figures and tables, in the case of MRC a small percentage of users are better off with max-min fair power allocation. In the other two schemes, although the efficiency of a small percentage of users is better with EPA, maxmin fair power allocation is superior to maximum power allocation of SINR products.

When interpreted in terms of power allocation algorithms, it is seen that the max-min fair power allocation algorithm tends to users with less SE due to its working principle. Thus, it is understood that these users are trying to increase SE. This applies to all three schemes. When examined in terms of all users, it is understood that the max product SINR power allocation method gives the best results in all schemes. The EPA algorithm, on the other hand, gives a result between these two in any case. In general, it is observed that the state of the CDF curves for all three power allocation algorithms is affected by the choice of signal detection schemes to consider for the uplink.

When focusing on the graph curves, it is seen that for any scheme other than MRC, if approximately 10 percent of the users have better channels, the SE is higher with EPA. In the case of MRC, although max-min fair power allocation is ahead in this regard, it is understood that the ratios are close to each other. However, as it can be noticed from the tables, in case a small portion of users have good channels, max-min fair power e-ISSN: $2148-2683$ allocation is at the forefront. If the random location of the users is taken into account and a certain SE value is required for the user at this location, the maximum power allocation method of SINR multiplications is a method that should be preferred.

Briefly, different results in SE of users for uplink are provided by power allocation. When evaluated in general, it has been observed that the maximum of SINR product power allocation algorithm mostly provides high SE. Which power allocation is effective for specific cases can be obtained from the results. In addition, the effect of the signal detection scheme to be used on the results is shown. Thus, the most suitable scheme can be selected.

\section{Conclusion}

In this study, power allocation strategies for Massive MIMO systems are detailed. With the advancement of next-generation wireless communication technologies, it is critical to enhance spectrum and EE, in particular. For this reason, studies of power allocation algorithms, especially on spectrum and EE, have been taken into account. The purpose of this study is not to explain the technical details of the studies on power allocation algorithms. It is to emphasize the conditions under which power allocation algorithms proposed in these studies are performed. Massive MIMO scenarios used by detailing these conditions are also revealed. In addition, performance metrics in these studies, which focus on spectrum and EE, are specified. The techniques used in the creation of the algorithm are detailed. Advantages and disadvantages of the studies are emphasized. Finally, the power allocation algorithms used in the benchmarking are also indicated. It is understood from this review study that there is a lot of work on power allocation algorithms, especially for next generation communication technologies. Since it is known that the Massive MIMO system also plays an important role, the work done for this system is also quite high.

After a general literature review of the power allocation algorithms, the power allocation strategies that are essentially covered in the literature were compared. These algorithms are EPA, max-min fair power allocation and SINR product maximum power allocation algorithm. As far as we know, there is no comparison of these three basic algorithms for the Massive MIMO system considering the SE in uplink transmission. The examination of the SE for the multi-cell Massive MIMO system was carried out in terms of power allocation algorithms. In addition, MRC, ZF and MMSE schemes were taken into account to observe the results according to the signal detection schemes.

In summary, the power allocation algorithms in Massive MIMO systems were examined especially for SE and EE. This study will also fill the gap in the literature regarding this situation. In addition, performing simulations of basic power allocation algorithms under signal detection schemes after a general evaluation is another contribution of this study. We hope it will be an incentive for researchers to study power allocation algorithms.

\section{References}

Bana, A.-S., Sanguinetti, L., Carvalho, E. De, \& Popovski, P. (2019). Outage Analysis of Downlink URLLC in Massive MIMO systems with Power Allocation. 2019 53rd Asilomar Conference on Signals, Systems, and Computers, 13941398.

https://doi.org/10.1109/IEEECONF44664.2019.9049046 
Bashar, M., Cumanan, K., Burr, A. G., Debbah, M., \& Ngo, H. Q. (2019). On the uplink max-min SINR of cell-free massive MIMO systems. IEEE Transactions on Wireless Communications. https://doi.org/10.1109/TWC.2019.2892463

Björnson, E., Hoydis, J., \& Sanguinetti, L. (2017). Massive MIMO Networks: Spectral, Energy, and Hardware Efficiency. Foundations and Trends ${ }^{\circledR}$ in Signal Processing, 11(3-4), 154-655. https://doi.org/10.1561/2000000093

Björnson, E., Larsson, E. G., \& Debbah, M. (2016). Massive MIMO for Maximal Spectral Efficiency: How Many Users and Pilots Should Be Allocated? IEEE Transactions on Wireless https://doi.org/10.1109/TWC.2015.2488634

Boccardi, F., Heath, R. W., Lozano, A., Marzetta, T. L., \& Popovski, P. (2014). Five disruptive technology directions for 5G. IEEE Communications Magazine, 52(2), 74-80. https://doi.org/10.1109/MCOM.2014.6736746

Chakraborty, S., Demir, O. T., Bjornson, E., \& Giselsson, P. (2020). Efficient Downlink Power Allocation Algorithms for Cell-Free Massive MIMO Systems. IEEE Open Journal of the Communications Society, 2(December 2020), 168186. https://doi.org/10.1109/ojcoms.2020.3044280

Chang Soon Park, \& Kwang Bok Lee. (2002). Transmit power allocation for BER performance improvement in multicarrier systems. The 13th IEEE International Symposium on Personal, Indoor and Mobile Radio Communications, 5, 2049-2053. https://doi.org/10.1109/PIMRC.2002.1046504

Chaves, R. S., Cetin, E., Lima, M. V. S., \& Martins, W. A. (2020). On the Convergence of Max-Min Fairness Power Allocation in Massive MIMO Systems. IEEE Communications Letters, 24(12), 2873-2877. https://doi.org/10.1109/LCOMM.2020.3014942

Cheng, R. S., \& Verdu, S. (1993). Gaussian multiaccess channels with ISI: capacity region and multiuser water-filling. IEEE Transactions on Information Theory, 39(3), 773-785. https://doi.org/10.1109/18.256487

Clerckx, B., \& Claude Oestges. (2013). Mimo Wireless Networks. In MIMO Wireless Networks. Elsevier. https://doi.org/10.1016/C2010-0-66925-2

Dikmen, O., \& Kulac, S. (2019). A new method in pilot reuse factor selection in spectrum efficient massive MIMO systems. Elektronika Ir Elektrotechnika. https://doi.org/10.5755/j01.eie.25.6.24829

Dikmen, O., \& Kulaç, S. (2021). Investigation of Ideal Number User Terminals with Spectrum Efficiency in Next Generation Wireless Communication Systems. Traitement Du Signal, 38(1), 115-126. https://doi.org/10.18280/ts.380112

Duman, T. M., \& Ghrayeb, A. (2007). Coding for MIMO Communication Systems. In Coding for MIMO Communication Systems. John Wiley \& Sons, Ltd. https://doi.org/10.1002/9780470724347

Gandotra, P., \& Jha, R. K. (2017). A survey on green communication and security challenges in $5 \mathrm{G}$ wireless communication networks. In Journal of Network and
Computer

https://doi.org/10.1016/j.jnca.2017.07.002

Applications.

Hawej, M., \& Shayan, Y. R. (2019). Evaluation of Massive MUMIMO Channel Estimation Based on Uplink AchievableSum Rate Criteria. 2019 IEEE Canadian Conference of Electrical and Computer Engineering (CCECE), 1-5. https://doi.org/10.1109/CCECE.2019.8861846

Hu, B., Sun, Q., Wang, J., \& Xu, C. (2014). Joint power allocation and antenna selection for energy-efficient OFDM D-MIMO systems. 2014 6th International Conference on Wireless Communications and Signal Processing, WCSP 2014. https://doi.org/10.1109/WCSP.2014.6992152

Ivanis, P., \& Drajic, D. (2003). Combined optimal power allocation and adaptive modulation for MIMO systems with imperfect CSI. 6th International Conference on Telecommunications in Modern Satellite, Cable and Broadcasting Service, 2003. TELSIKS 2003., 1, 167-170. https://doi.org/10.1109/TELSKS.2003.1246208

Khalighi, M. A., Brossier, J.-M., Jourdain, G. V., \& Raoof, K. (2001). Water filling capacity of Rayleigh MIMO channels. 12th IEEE International Symposium on Personal, Indoor and Mobile Radio Communications. PIMRC 2001. Proceedings (Cat. No.01TH8598), 1, A-155-A-158. https://doi.org/10.1109/PIMRC.2001.965411

Kshetrimayum, R. S. (2017). Fundamentals of MIMO Wireless Communications. In Fundamentals of MIMO Wireless Communications. https://doi.org/10.1017/9781108234993

Larsson, E., Edfors, O., Tufvesson, F., \& Marzetta, T. (2014). Massive MIMO for next generation wireless systems. IEEE Communications Magazine, 52(2), 186-195. https://doi.org/10.1109/MCOM.2014.6736761

Liu, P., Jin, S., Jiang, T., Zhang, Q., \& Matthaiou, M. (2017). Pilot Power Allocation Through User Grouping in Multi-Cell Massive MIMO Systems. IEEE Transactions on Communications. https://doi.org/10.1109/TCOMM.2016.2645767

Marzetta, T. L. (2010). Noncooperative Cellular Wireless with Unlimited Numbers of Base Station Antennas. IEEE Transactions on Wireless Communications, 9(11), 3590 3600. https://doi.org/10.1109/TWC.2010.092810.091092

Marzetta, T. L., Larsson, E. G., Yang, H., \& Ngo, H. Q. (2016). Fundamentals of Massive MIMO. In Fundamentals of Massive MIMO. Cambridge University Press. https://doi.org/10.1017/CBO9781316799895

MIMO Systems, Theory and Applications. (2011). In H. Khaleghi Bizaki (Ed.), MIMO Systems, Theory and Applications. InTech. https://doi.org/10.5772/610

Nezamalhosseini, S. A., \& Chen, L. R. (2021). Optimal power allocation for mimo underwater wireless optical communication systems using channel state information at the transmitter. IEEE Journal of Oceanic Engineering. https://doi.org/10.1109/JOE.2019.2963551

Ngo, H. Q., Larsson, E. G., \& Marzetta, T. L. (2013). Energy and spectral efficiency of very large multiuser MIMO systems. IEEE Transactions on Communications, 61(4), 1436-1449. https://doi.org/10.1109/TCOMM.2013.020413.110848 
Phan, K., Le, L., Vorobyov, S., \& Le-Ngoc, T. (2009). Power Allocation and Admission Control in Multiuser Relay Networks via Convex Programming: Centralized and Distributed Schemes. EURASIP Journal on Wireless Communications and Networking, 2009(1), 901965. https://doi.org/10.1155/2009/901965

Prayongpun, N., \& Raoof, K. (2007). MIMO Channel Capacity with Polarization Diversity and Power Allocation Technique. 2007 IEEE International Conference on Signal Processing and Communications, 185-188. https://doi.org/10.1109/ICSPC.2007.4728286

Rusek, F., Persson, D., Buon Kiong Lau, Larsson, E. G., Marzetta, T. L., \& Tufvesson, F. (2013). Scaling Up MIMO: Opportunities and Challenges with Very Large Arrays. IEEE Signal Processing Magazine, 30(1), 40-60. https://doi.org/10.1109/MSP.2011.2178495

Shannon, C. E. (1948). A Mathematical Theory of Communication. Bell System Technical Journal, 27(3), 379-423. 7305.1948.tb01338.x https://doi.org/10.1002/j.1538-

Tan, C. W. (2014). Wireless network optimization by perronfrobenius theory. Foundations and Trends in Networking, 9(2-3), 107-218. https://doi.org/10.1561/1300000048

Tan, F., Chen, H., Zhao, F., \& Li, X. (2018). Energy-efficient power allocation for massive MIMO-enabled multi-way AF relay networks with channel aging. EURASIP Journal on Wireless Communications and Networking, 2018(1), 206. https://doi.org/10.1186/s13638-018-1222-2

Van Chien, T., Bjornson, E., \& Larsson, E. G. (2016). Joint power allocation and user association optimization for massive MIMO systems. IEEE Transactions on Wireless Communications.

https://doi.org/10.1109/TWC.2016.2583436

Van Chien, T., Bjornson, E., \& Larsson, E. G. (2018). Joint pilot design and uplink power allocation in multi-cell massive MIMO systems. IEEE Transactions on Wireless Communications.

https://doi.org/10.1109/TWC.2017.2787702

Verenzuela, D., Bjornson, E., \& Matthaiou, M. (2021). Optimal Per-Antenna ADC Bit Allocation in Correlated and CellFree Massive MIMO. IEEE Transactions on Communications, $1-1$. https://doi.org/10.1109/TCOMM.2021.3067699

Vucetic, B., \& Yuan, J. (2003). Space-Time Coding. In SpaceTime Coding. John Wiley \& Sons, Ltd. https://doi.org/10.1002/047001413X

Wang, C.-X., Haider, F., Gao, X., You, X.-H., Yang, Y., Yuan, D., Aggoune, H., Haas, H., Fletcher, S., \& Hepsaydir, E. (2014). Cellular architecture and key technologies for $5 \mathrm{G}$ wireless communication networks. IEEE Communications Magazine, 52(2), 122-130. https://doi.org/10.1109/MCOM.2014.6736752

Wu, Y., Liu, T., Cao, M., Li, L., \& Xu, W. (2018). Pilot contamination reduction in massive MIMO systems based on pilot scheduling. EURASIP Journal on Wireless Communications and Networking, 2018(1), 21. https://doi.org/10.1186/s13638-018-1029-1
Wubben, D., \& Lang, Y. (2008). Near-Optimum Power Allocation for Outage Restricted Distributed MIMO Multi-Hop Networks. IEEE GLOBECOM 2008 - 2008 IEEE Global Telecommunications Conference, 1-5. https://doi.org/10.1109/GLOCOM.2008.ECP.862

Xi Zhang, \& Ottersten, B. (2003). Power allocation and bit loading for spatial multiplexing in MIMO systems. 2003 IEEE International Conference on Acoustics, Speech, and Signal Processing, 2003. Proceedings. (ICASSP '03)., 5, V53-56. https://doi.org/10.1109/ICASSP.2003.1199866

Yang, H., \& Marzetta, T. L. (2017). Massive MIMO with MaxMin Power Control in Line-of-Sight Propagation Environment. IEEE Transactions on Communications. https://doi.org/10.1109/TCOMM.2017.2725262

Yoshimoto, A., \& Hattori, T. (2007). Area Coverage of a MultiLink MIMO System with Water Filling Power Allocation Strategy. 2007 IEEE 66th Vehicular Technology Conference, $1137-1141$ https://doi.org/10.1109/VETECF.2007.246 